\title{
Antimicrobial drugs for persistent diarrhoea of unknown or non-specific cause in children under six in low and middle income countries: systematic review of randomized controlled trials
} Katharine Abba*, Rebecca Sinfield, C Anthony Hart and Paul Garner

Address: Liverpool School of Tropical Medicine, Pembroke Place, Liverpool, L3 5QA, UK

Email: Katharine Abba* - K.abba@liverpool.ac.uk; Rebecca Sinfield - Becca.sinfield@talk21.com; Paul Garner - pgarner@liverpool.ac.uk

* Corresponding author

Published: 3 March 2009

BMC Infectious Diseases 2009, 9:24 doi:10.1 186/147/-2334-9-24

This article is available from: http://www.biomedcentral.com/I47I-2334/9/24

(C) 2009 Abba et al; licensee BioMed Central Ltd.

This is an Open Access article distributed under the terms of the Creative Commons Attribution License (http://creativecommons.org/licenses/by/2.0), which permits unrestricted use, distribution, and reproduction in any medium, provided the original work is properly cited.
Received: 19 August 2008

Accepted: 3 March 2009

\begin{abstract}
Background: A high proportion of children with persistent diarrhoea in middle and low income countries die. The best treatment is not clear. We conducted a systematic review to evaluate the effectiveness of antimicrobial drug treatment for persistent diarrhoea of unknown or non-specific cause.

Methods: We included randomized comparisons of antimicrobial drugs for the treatment of persistent diarrhoea of unknown or non-specific cause in children under the age of six years in low and middle income countries. We searched the electronic databases MEDLINE, EMBASE, LILACS, WEB OF SCIENCE, and the Cochrane Central Register of Controlled Trials (CENTRAL) to May 2008 for relevant randomized or quasi randomized controlled trials. We summarised the characteristics of the eligible trials, assessed their quality using standard criteria, and extracted relevant outcomes data. Where appropriate, we combined the results of different trials.

Results: Three trials from South East Asia and one from Guatemala were included, all were small, and three had adequate allocation concealment. Two were in patients with diarrhoea of unknown cause, and two were in patients in whom known bacterial or parasitological causes of diarrhoea had been excluded. No difference was demonstrated for oral gentamicin compared with placebo (presence of diarrhoea at 6 or 7 days; 2 trials, $n=15 \mathrm{I}$ ); and for metronidazole compared with placebo (presence of diarrhoea at 3, 5 and 7 days; I trial, $n=99$ ). In one small trial, sulphamethoxazole-trimethoprim appeared better than placebo in relation to diarrhoea at seven days and total stool volume $(n=55)$.
\end{abstract}

Conclusion: There is little evidence as to whether or not antimicrobials help treat persistent diarrhoea in young children in low and middle income countries.

\section{Background}

In 2002, diarrhoea caused an estimated $13.2 \%$ of child deaths worldwide[1], most of them in children under the age of five years in low and middle income countries[2]. In this group, around $3 \%$ to $19 \%$ of acute diarrhoea epi- sodes become persistent [3] and some experts estimate that up to $50 \%$ of diarrhoea deaths may be due to persistent diarrhoea[1]. As the number of deaths from acute diarrhoea reduces following widespread use of oral rehydration therapy, the contribution of persistent diarrhoea 
to overall diarrhoea mortality is increasing. Persistent diarrhoea also adversely affects nutritional status, and is often associated with malnutrition. In one study, three months after a persistent diarrhoea episode, children had significantly lower weight for age and weight for height $\mathrm{Z}$ scores than three months before the episode [4].

Children living in poor areas with poor hygiene and sanitation conditions and children with poor nutritional status are most at risk of developing persistent diarrhoea[3]. As poor nutrition is both a risk factor and a consequence of persistent diarrhoea, the two are very commonly associated. Children with HIV/AIDS are at particular risk; at initial presentation to hospital with HIV/AIDS, around 36-50\% [5-7] of children have persistent diarrhoea. Dysentery and more severe diarrhoeal illness are more likely to become persistent than milder episodes[3]. Previous antibiotic use and irrational use of antibiotics for acute diarrhoea are also considered to be risk factors[3] for persistent diarrhoea.

\section{Definition and causes}

The World Health Organization (WHO) defines diarrhoea as the passing of three or more loose stools (which take the shape of a container) within a 24 hour period. A new episode of diarrhoea can occur after two full days without diarrhoea. Episodes of diarrhoea lasting for less than 14 days are defined as acute, episodes lasting for 14 or more days are defined as persistent.

The causes of persistent diarrhoea in populations are complex and poorly understood, and in individuals are often unknown. Pathogens associated with persistent diarrhoea are also often found in healthy children without diarrhoea[4], a finding highlighted in our related review of pathogens found in the stool of children with persistent diarrhoea and without diarrhoea, to be published at a later date. Some, such as Cryptosporidium, Giardia lamblia and enteroaggregative Escherichia coli (EAggEC) are thought to be associated with persistent diarrhoea[3] in some locations. Children with persistent diarrhoea who are HIV positive may have different patterns of enteric pathogens than those who are HIV negative[8]. In addition, the diarrhoea may be caused by multiple factors: malnutrition, micronutrient deficiencies, milk or food intolerance, or diseases of the bowel, as well as prior antimicrobial therapy[9].

\section{Treatment}

The current recommendations of Integrated Management of Childhood Illness programme[10] for treating diarrhoea is that children with bloody diarrhoea are treated with antimicrobials for Shigella, or for Entamoeba histolytica where the organism is detected in the stool; it is recommended that children with watery diarrhoea are not treated with antimicrobials; except where Giardia lamblia is found.

Even where an enteric pathogen is detected in children with persistent diarrhoea, it is not always clear that this is the cause of the illness. In addition, health workers in low and middle income countries often do not have access to sufficient high quality diagnostic laboratory facilities to analyse stool samples for all children with diarrhoea. In these situations treatment needs to be syndromic, based on symptoms and the mostly likely cause of the symptoms; and may include replacement fluid and electrolytes, nutritional rehabilitation and sometimes drug treatment[9].

Recent studies have suggested that antimicrobial treatment may be useful in causes of watery diarrhoea other than Giardia lamblia. For example, there have been promising trials looking at the use of nitazoxanide for children with diarrhoea associated with Cryptosporidium infection[11], and ciprofloxacin for diarrhoea associated with enteroaggregative E.coli in adults with AIDS[12]. However, these are yet to be demonstrated in a systematic review or large scale trial in children with persistent diarrhoea. The use of antimicrobials needs to be approached with caution due to potential problems of drug resistance and possible reactions of some micro-organisms: enterohaemorrhagic E coli (EHEC) may release toxins more readily when a person is treated with certain drugs, potentially causing severe illness[13].

Given the lack of diagnostic facilities, and the consequent requirement that children presenting to health facilities with persistent diarrhoea receive only presumptive treatment, we conducted a systematic review. This project was originally requested by $\mathrm{WHO}$, due to lack of evidence in this area.

\section{Objective}

To assess the effectiveness of antimicrobial drugs for the treatment of persistent diarrhoea of unknown or non-specific aetiology in children under the age of six years in low and middle income countries. Only children under the age of six were included, because this age group are most at risk from death or serious morbidity relating to persistent diarrhoea.

\section{Criteria for including studies in this review Types of studies}

Randomized and quasi-randomized controlled trials.

\section{Types of participants}

Children under the age of six years, with diarrhoea of unknown or non-specific aetiology longer than 14 days duration, in a low or middle income country setting (as 
defined by the World Bank). Trials including only participants with a known cause for their diarrhoea were excluded. Trials including people of different ages or with diarrhoea of different durations were included if data relating only children under the age of six with persistent diarrhoea could be extracted.

\section{Types of intervention}

Intervention: any antimicrobial drug treatment regimen plus usual care

Control: placebo or usual care

Types of outcome

Primary:

Duration of diarrhoea

Secondary:

Presence of diarrhoea at follow-up

Need for hospitalisation

Stool volume

Death

Adverse events:

Any adverse events

\section{Search strategy for identification of studies}

The search strategy was developed in collaboration with an information retrieval specialist (see below). The strategy listed applies to Medline and was amended where necessary to search the other databases listed. No language restrictions were applied. The reference lists of included studies were also scrutinised for additional relevant studies. The last search was undertaken May 202008.

\section{Search Strategy}

Databases searched

MEDLINE (1966 to March 2007) via the OVID interface (table 1 for strategy).

EMBASE (1980 to March 2007) via the OVID interface.

LILACS database - Latin American and Caribbean Health Sciences Literature (1982 to date) - via Virtual Health Library interface.

WEB OF SCIENCE (Science Citation Index Expanded 1945 to present).

Cochrane Central Register of Controlled Trials (CENTRAL), published in The Cochrane Library.

\section{Search strategy in MEDLINE}

1. persistent (diarrhea OR diarrhoea) ti, ab

2. chronic (diarrhea OR diarrhoea) ti, ab.

3. watery (diarrhea OR diarrhoea) ti, ab

4. (diarrheal disease*) OR (diarrhoeal disease*) ti, ab

Table I: Reasons for excluding reports initially identified as relevant

\begin{tabular}{ll}
\hline Reason for exclusion & Number of reports \\
\hline Did not assess the use of antimicrobials & 14 \\
\hline Included only patients with a specific cause of diarrhoea & 6 \\
\hline Used an alternative definition of persistent diarrhoea & 3 \\
\hline Included adults only & 3 \\
\hline Included children with acute diarrhoea only & 3 \\
\hline Were review articles & 3 \\
\hline Had no control group or were case studies & 1 \\
\hline Were undertaken in a high income country & 1 \\
\hline Relevant controlled trial but no mention of randomization & 3 \\
\hline
\end{tabular}


6. 1 OR 2 OR 3 OR 4) NOT cancer NOT (inflammatory bowel disease $^{*}$ ) NOT (ulcerative colitis)

7. child* OR infant* OR pediatr* $t i, a b$

\section{6 AND 7}

9. Diarrhea, infantile/drug therapy [MeSH] OR Diarrhea, infantile/prevention and control [MeSH] OR Diarrhea, infantile/therapy [MeSH]

10. Diarrhea/drug therapy [MeSH] OR Diarrhea/prevention and control [MeSH] OR Diarrhea/therapy [MeSH]

11. therap* OR treatment OR treating ti, ab

\section{9 OR 10 OR 11}

13. Anti-Infective Agents/administration and dosage [MeSH] OR Anti-Infective Agents/adverse effects [MeSH] OR Anti-Infective Agents/therapeutic use [MeSH])

14. Antiprotozoal Agents/administration and dosage [MeSH] OR Antiprotozoal Agents/adverse effects [MeSH] OR Antiprotozoal Agents/therapeutic use [MeSH])

15. Antiparasitic Agents/administration and dosage [MeSH] OR Antiparasitic Agents/adverse effects [MeSH] OR Antiparasitic Agents/therapeutic use [MeSH])

\section{12 OR 13 OR 14 OR 15}

\section{8 AND 16}

18. randomized controlled trial [pt] OR controlled clinical trial [pt] OR randomized controlled trials [MeSH] OR controlled clinical trials [MeSH] OR random allocation [MeSH] OR double-blind method [MeSH] OR singleblind method [MeSH]

OR (placebos [MeSH] OR placebo* ti, ab OR random* ti, ab OR quasi-random* $\mathrm{ti}$, ab

\section{17 AND 18}

\section{Methods}

\section{Study selection}

Two reviewers independently inspected titles and abstracts identified in the initial literature search in order to identify potentially relevant publications. All potentially relevant publications identified by at least one reviewer were obtained in full text format. One reviewer then applied the inclusion criteria to select which trials to include in the review, and scrutinised publications for duplication of trial results.

\section{Assessment of methodological quality}

Two reviewers independently assessed the methodological quality of the included trials, using a pro-forma as a guide. The methodological quality of the included trials was assessed in terms of generation of the allocation sequence and allocation concealment and reported as adequate, inadequate or unclear according to Juni 2001[14]. We recorded who was blinded in each trial. We classified inclusion of randomized participants in the analysis as adequate if $80 \%$ or more of the participants are included in the analysis, unclear if not described, and inadequate if less than $80 \%$ were included. Any disagreements were resolved by discussion.

\section{Characteristics of included trials}

One reviewer summarised the characteristics of the included trials. Information was extracted on the trial setting, location, start date, participant characteristics (such as age, sex and nutritional status), number of participants, intervention, control and outcomes for each trial. We also noted any acknowledged sources of financial support for the trial.

\section{Data extraction}

One author extracted outcomes data for the intervention and control groups. For dichotomous data we extracted the number of participants with the outcome, the total number randomized to each group, and the total number included in the analysis. For continuous data we extracted the number of participants in each group, the arithmetic mean and their standard deviations, where available.

\section{Data analysis}

The analysis was undertaken using RevMan 4.2 software. For dichotomous data we calculated relative risks and where appropriate combined results from different trials. Where continuous data were summarized by arithmetic means, we summarized the results using weighted mean difference (WMD). We stratified the analysis by class of antimicrobial drug used. We presented data on adverse events in a narrative summary.

\section{Results \\ Studies identified}

Four trials met our inclusion criteria. The initial search identified 378 publications, from which we selected 43 that appeared, from their abstracts or titles, to be potentially relevant, for retrieval of the full text. We were unable to assess three reports due to time constraints, one because it was not available within the UK, and two, published in Polish and Ukrainian respectively, because translators were not available within the available time period. Of the 40 papers that we were able to assess, three were reports of trials eligible for inclusion in the review. The reasons for the exclusion of the other 37 are summarised 
in Table 1. We identified one additional eligible trial through reading the reference lists of retrieved review articles.

\section{Characteristics of included trials}

The characteristics of the four included trials are summarised in Table 2, and also described below.

\section{Location}

Three trials were undertaken in the South East Asia region; two in India[15,16] and one in Bangladesh[17]. Another was undertaken in Guatemala [18].

\section{Dates of fieldwork}

Two trials recruited participants during the period 1988 to $1990[15,18]$. Two trial reports did not provide dates for the fieldwork; these were published in 1995[17] and 1996 [16] respectively.

\section{Participants}

Each trial included children of a slightly different age range, the total age range being three months to four years. Three trials excluded children with diarrhoea lasting over a certain length of time (18 days[18], 4 weeks[16] and 6 weeks[17] respectively). Three trials excluded children with dysentery or with blood in the stool $[15,16,18]$, and the other[17] excluded children with Shigella or Enta-

Table 2: Characteristics of Included Trials

\begin{tabular}{|c|c|c|c|c|c|}
\hline $\begin{array}{l}\text { Location and date of } \\
\text { publication }\end{array}$ & Participants & Setting & Interventions & Outcomes & Source of Support \\
\hline $\begin{array}{l}\text { Guatemala } \\
\text { I992 [18] }\end{array}$ & $\begin{array}{l}\text { Number: } 102 \\
\text { Girls and boys, 3-35 } \\
\text { mths } \\
\text { Diarrhoea 14-18 } \\
\text { days, weight for length } \\
\text { not } \\
<-2 \text { Z, no dysentery }\end{array}$ & $\begin{array}{l}\text { Surveillance project: } \\
\text { rural indigenous } \\
\text { community } \\
\text { Field nurse visited } \\
\text { homes three times } \\
\text { daily to deliver } \\
\text { intervention }\end{array}$ & $\begin{array}{l}\text { Group I: } 10 \text { mg oral } \\
\text { gentamicin sulphate } \\
\text { per kg body weight } \\
\text { per day: } 3 \times \text { daily for } 5 \\
\text { days. } \\
\text { Group 2: Placebo: } 1 \% \\
\text { magnesium sulphate } \\
3 \times \text { daily for } 5 \text { days. }\end{array}$ & $\begin{array}{l}\text { Diarrhoea stopped at } \\
7 \text { days, and at least } 48 \\
\text { hrs after end of } \\
\text { treatment }\end{array}$ & None stated \\
\hline India 1992 [15] & $\begin{array}{l}\text { Number: } 68 \\
\text { Boys, } 3 \text { mths to } 4 \text { yrs } \\
\text { Diarrhoea } \geq 14 \text { days, } \\
\text { weight for length } \leq \\
90 \% \text { of standard, no } \\
\text { dysentery }\end{array}$ & $\begin{array}{l}\text { Hospital oral } \\
\text { rehydration unit in } \\
\text { New Delhi } \\
\text { Field worker visited } \\
\text { homes twice daily to } \\
\text { deliver intervention } \\
\text { and leave evening } \\
\text { dose }\end{array}$ & $\begin{array}{l}\text { Group I: } 50 \text { mg oral } \\
\text { gentamicin per kg } \\
\text { body weight per day: } \\
4 \text { times daily for } 6 \\
\text { days } \\
\text { Group 2: Placebo }\end{array}$ & $\begin{array}{l}\leq 2 \text { liquid stools per } \\
\text { day at } 6 \text { days. } \\
\text { Intake of IV fluids, } \\
\text { ORS, water and } \\
\text { energy. } \\
\text { Output of diarrhoea, } \\
\text { vomit and urine. } \\
\text { Weight change at } 168 \\
\text { hrs }\end{array}$ & $\begin{array}{l}\text { Diarrhoeal Diseases } \\
\text { Control Programme, } \\
\text { World Health } \\
\text { Organization }\end{array}$ \\
\hline India 1996 [16] & $\begin{array}{l}\text { Number: I } 56 \\
\text { Girls and boys, } 4 \text { mths } \\
\text { to } 3 \text { yrs } \\
\text { Diarrhoea } \geq 14 \text { days } \\
<4 \text { weeks, no } \\
\text { dysentery, Giardia } \\
\text { lamblia or Entamoeba } \\
\text { histolytica, no illness } \\
\text { requiring antibiotics }\end{array}$ & $\begin{array}{l}\text { Surveillance project } \\
\text { with referrals to clinic } \\
\text { and direct clinic } \\
\text { attendances: urban } \\
\text { slum in Delhi } \\
\text { (outpatients) }\end{array}$ & $\begin{array}{l}\text { Group I: } 30 \text { mg oral } \\
\text { metronidazole plus } 50 \\
\text { mg oral nalidixic acid } \\
\text { per kg body weight: } \\
3 \times \text { daily for } 7 \text { days } \\
\text { Group 2: } 30 \text { mg oral } \\
\text { metronidazole per kg } \\
\text { body weight: } 3 \times \text { daily } \\
\text { for } 7 \text { days } \\
\text { Group 3: Placebo }\end{array}$ & $\begin{array}{l}\text { First of } 3 \text { days with }< \\
3 \text { liquid stools in a } 24 \\
\text { hrs; days } 3,5 \text { and } 7 . \\
\text { No. stools in previous } \\
24 \text { hrs; days } 2,5 \text { and } \\
7 . \\
\text { Weight change at days } \\
7 \text { and I } 4\end{array}$ & $\begin{array}{l}\text { CDR, World Health } \\
\text { Organization }\end{array}$ \\
\hline Bangladesh 1995 [17] & $\begin{array}{l}\text { Number: } 55 \\
\text { Girls and boys, } 6 \text { to } \\
\text { I } 5 \text { mths } \\
\text { Diarrhoea } \geq 14 \text { days } \\
<6 \text { weeks No } \\
\text { systemic infection, } \\
\text { antibacterial use } \\
\text { previous } 7 \text { days, } \\
\text { severe malnutrition, } \\
\text { Vibrio cholerae, } \\
\text { Salmonella, Shigella, } \\
\text { Giardia lamblia or } \\
\text { Entamoeba histolytica }\end{array}$ & $\begin{array}{l}\text { Clinical research unit } \\
\text { of specialist diarrhoea } \\
\text { hospital } \\
\text { (inpatients) }\end{array}$ & $\begin{array}{l}\text { Group I: } 10 \text { mg oral } \\
\text { trimethoprim plus } 50 \\
\text { mg } \\
\text { sulphamethoxazole } \\
\text { per kg body weight; } \\
2 \times \text { daily for } 7 \text { days } \\
\text { Group 2: Placebo, }\end{array}$ & $\begin{array}{l}\text { Diarrhoea stopped at } \\
7 \text { days. } \\
\text { Stool output }(\mathrm{g} / \mathrm{kg}) \\
\text { days } \mathrm{I}, 2,3,4,5,6 \text { and } 7 \text {, } \\
\text { plus all days } \mathrm{I}-7 \\
\text { combined. } \\
\text { Duration of diarrhoea. } \\
\text { Hospital infection. } \\
\text { Energy intake } \\
\text { (kcal/kg/day) }\end{array}$ & $\begin{array}{l}\text { United States Agency } \\
\text { for International } \\
\text { Development and the } \\
\text { International Centre } \\
\text { for Diarrhoeal } \\
\text { Disease Research, } \\
\text { Bangladesh }\end{array}$ \\
\hline
\end{tabular}


moeba histolytica (the main causes of dysentery). One trial excluded children described as 'severely malnourished', another stipulated that weight for length was not less than $-2 \mathrm{Z}[17,18]$, while another included only children who had weight for length less than or equal to $90 \%$ of the standard [15]. Two trials excluded children with systemic infection[16,17], and one excluded children who had taken antibiotics in the previous seven days[17]. Two excluded children with specific enteric pathogens (Giardia lamblia and Entamoeba histolytica in one[16], Giardia lamblia, Entamoeba histolytica, Vibrio cholerae, Salmonella and Shigella another[17]). None included specifically children with HIV/AIDS.

\section{Settings}

Participants were recruited from a range of sources including a diarrhoea surveillance project within a rural indigenous community[18], referrals to a hospital rehydration unit[15], and attendance at a clinic provided as part of a surveillance project in an urban slum[16]. In one trial it was not clear how the participants were recruited[17]

\section{Comparisons}

Two trials compared gentamicin with placebo[15,18], one three-arm trial compared metronidazole, metronidazole combined with nalidixic acid, and placebo[16], and one trial compared sulphamethoxazole-trimethoprim with placebo[17]. All antimicrobials were given orally for between five and seven days.

\section{Outcomes}

Only one trial reported on our primary outcome of duration of diarrhoea[17]. All four trials reported on recovery from diarrhoea by the end of treatment; one trial also assessed diarrhoea at three and five days[16]. Three trials reported on stool output at various time points; two measured stool weight $[15,17]$, and one measured number of stools[16]. In addition, two trials reported on weight gain at different time intervals $[15,16]$, one reported on various fluid intakes and outputs[15], two reported on energy intake[15,17], and one reported on hospital-acquired infections[17]. Two trials recorded and reported on adverse events[15,18].

\section{Sources of support}

Two trials were supported by the World Health Organization $[15,16]$, one by the United States Agency for International Development and International Centre for Diarrhoeal Disease Research[17], and one did not mention a source of support[18]. None acknowledged support from pharmaceutical companies.

\section{Quality assessment}

A summary of the methodological quality assessment for each study is presented in Table 3. All four studies described blinding the participants to which group they were in, and including over $80 \%$ of the randomized participants in the main analyses. Three studies also reported adequate generation of allocation sequence, allocation concealment and blinding of service providers and outcomes assessors. The remaining study[16] was unclear on these methodological issues, but stated that it used randomization, and that it used coded antimicrobial and placebo preparations, which were identical in appearance.

\section{Outcomes}

Oral gentamicin versus placebo

Two trials[15,18] compared oral gentamicin $(10 \mathrm{mg} / \mathrm{kg}$ body weight in one trial and $50 \mathrm{mg} / \mathrm{kg}$ body weight in the other) versus placebo. Both trials assessed and reported on presence of diarrhoea at end of treatment ( 6 or 7 days). Combining the results of the two trials, there was no difference between the gentamicin and placebo groups in the number of children with diarrhoea at the end of treatment (relative risk $1.04,95 \%$ CI 0.78 to $1.38,151$ participants); around half the children in both groups recovered within six or seven days. There was no difference in point estimates between the two trials, one of which excluded children with weight for length less than $-2 \mathrm{Z}$ and used $\mathrm{a}$ standard dose of gentamicin [18], $(R R=0.01)$, and one of which included only children with weight for length equal to or less than $90 \%$ of the standard and used a massive

Table 3: Methodological quality assessment of included trials

\begin{tabular}{lllllll}
\hline Location and reference & $\begin{array}{l}\text { Generation of allocation } \\
\text { sequence }\end{array}$ & Concealment of allocation & Blinding & & & $\begin{array}{c}\text { Percentage of participants } \\
\text { included in the analysis }\end{array}$ \\
\cline { 4 - 7 } & & & Participants & Providers & Outcomes assessors \\
\hline Guatemala [17] & Adequate & Adequate & Yes & Yes & Yes & Adequate \\
\hline India [14] & Adequate & Adequate & Yes & Yes & Yes & Adequate \\
\hline India [15] & Unclear & Unclear & Yes & Unclear Unclear & Adequate \\
\hline Bangladesh [16] & Adequate & Adequate & Yes & Yes & Yes & Adequate
\end{tabular}


dose of gentamicin with the aim of eradicating aerobic bacterial overgrowth of the small intestine [15] $(\mathrm{RR}=$ $0.10)$. There were also no significant differences between groups in any reported measure of weight gain, fluid intake, energy intake, or fluid output.

One trial reported no drug-related untoward effects[18]. The other reported no clinical toxicity, and blood urea concentrations similar in the treatment and placebo groups[15].

\section{Metronidazole combined with nalidixic acid versus metronidazole alone versus placebo alone}

One trial[16] compared three treatment groups: metronidazole combined with nalidixic acid, metronidazole alone and placebo. There was no significant difference between the groups in the primary outcome of time to recovery, or in the number of children with diarrhoea at three, five or seven days, although point estimates tended to favour the group receiving metronidazole combined with nalidixic acid.

There were no significant differences between groups in the mean number of stools in the previous 24 hours at three days or five days; at seven days the group receiving metronidazole combined with nalidixic acid had fewer stools than the group receiving metronidazole alone but the difference was small (mean difference -1.10, 95\% confidence interval -2.07 to $-0.13,99$ participants), and not significantly different when compared with the placebo group. There were no differences between the groups in percentage weight gain at seven and 14 days.

Adverse events were not mentioned in the report of this trial.

\section{Sulphamethoxazole-trimethoprim versus placebo}

One trial compared sulphamethoxazole-trimethoprim with placebo[17]. Significantly fewer children in the treatment group had diarrhoea at the end of treatment ( 7 days) (relative risk $0.4,95 \%$ confidence interval 0.16 to $0.99,55$ participants). This related to an $82 \%$ cure rate in the antimicrobials group and 55\% cure rate in the placebo group. Duration of diarrhoea also appeared to favour treatment, but the difference was not significant. Total stool output in the seven days following start of treatment was significantly lower in the treatment group (mean difference $179.4 \mathrm{~g}$, 95\% confidence interval -340.20 to -18.60 ).

Participants in the treatment group had a significantly lower risk of acquiring infections while in hospital compared with placebo (relative risk 0.06, 95\% confidence interval 0.01 to 0.54 ); while energy intake from the hospital diet was similar in both groups.
Adverse events were not mentioned in the report of this trial.

\section{Discussion}

Despite the comprehensive search strategy used, we identified only four trials assessing the use of antimicrobials for children with persistent diarrhoea in low and middle income countries; all of which were conducted in the late 1980 s and early 1990s. All four trials used good quality methods to minimise the risk of bias. However, they are also all quite small, involving between 55 and 156 participants; and so the effect estimates are consequently imprecise. Two trials excluded children with certain laboratoryconfirmed pathogens known to cause diarrhoea found in the stool, while the other two trials did not test the participants for specific pathogens. Two trials included only children with associated malnutrition or low weight for height. None of the studies included children with known HIV/AIDS.

In a related review that has been submitted for publication, we examined the frequency of different pathogens found in children with persistent diarrhoea and no diarrhoea. We found that, while children with persistent diarrhoea are more likely to have at least one detectable enteric pathogen than children without diarrhoea, for specific pathogens there were no significant differences between the two groups; both exhibit a wide range of different pathogens in the stool, including bacteria, parasites and viruses. These findings suggest that antimicrobial therapy may be of limited effectiveness in the majority of children with persistent diarrhoea. Trials of oral gentamicin, a non-absorbable drug effective against a wide range of bacteria, have tended to confirm this. Small trials of sulphamethoxazole-trimethoprim, and metronidazole combined with nalidixic acid have suggested some potentially worthwhile effects, which have not been tested in larger trials. Both these combinations are absorbable and effective against a wide range of bacteria; possible modes of action therefore include direct action on the enteric pathogens, and also on any systemic infections which may be delaying the child's recovery from diarrhoea.

\section{Conclusion}

There is limited evidence as to whether or not antimicrobials help to reduce the duration of persistent diarrhoea or reduce its health impact in young children in developing countries, either in children with a symptomatic diagnosis of persistent diarrhoea where no laboratory exists, or in children with persistent diarrhoea in whom known bacterial and parasitic causes have been excluded. There is currently insufficient data to recommend the use of any kind of antibiotic in persistent diarrhoea of unknown cause or non-specific cause, and hence no implications for current guidelines on the treatment of persistent diarrhoea. 
Further good quality trials, of sufficient sample size to detect clinically important effect sizes, are needed to evaluate the use of antimicrobials in the presumptive treatment of persistent diarrhoea. These trials should be conducted in areas where persistent diarrhoea is common in young children, and where testing for enteric pathogens is not routinely available. Children with HIV/AIDS should be included. Trials should first assess the treatment combinations that have already given encouraging results in previous, smaller trials, and then perhaps other widespectrum antimicrobial drug combinations. Outcomes should include nutritional recovery, which will require a longer period of follow-up than that of the trials included in this review. Monitoring of emerging pathogen resistance should be undertaken within these trials.

\section{Competing interests}

The authors declare that they have no competing interests.

\section{Authors' contributions}

KA wrote the review protocol, inspected the initial search results for potentially relevant publications, selected studies for inclusion, extracted data, undertook the data analysis and drafted the manuscript. RS inspected the initial search results for potentially relevant publications, extracted data, and assisted in the interpretation of data. $\mathrm{CAH}$ provided technical advice and assisted in the interpretation of the findings. PG conceived of the study, secured its funding, participated in the design, assisted with the interpretation of data and helped to draft the manuscript. PG, KA and RS read and approved the final manuscript. CAH died before the completion of the manuscript. He was a Professor within the Department of Infections and Host Defence, School of Medicine, University of Liverpool.

\section{Acknowledgements}

Vittoria Lutje devised the search strategy and ran the search.

This review was jointly funded by the UK Department for International Development (DFID) for the benefit of developing countries; and by a grant from the World Health Organization.

\section{References}

I. Mathers CD, Bernard C, Moesgaard IK, Inoue M, Ma Fat D, Shibuya $\mathrm{S}$, Stein $\mathrm{C}$, Tomijima N, Xu H: Global burden of disease in 2002: data sources, methods and results. Global programme on evidencefor health policy discussion paper no. 54. (revised 2004). 2003 [http://www.who.int/healthinfo/paper54.pdf]. World Health Organization

2. Murray C, Lopez A, eds: Global health statistics: a compendium of incidence, prevalence an mortality estimates for over $\mathbf{2 0 0}$ conditions. Cambridge, MA: Harvard School of Public Health on behalf of the World Health Organization and World Bank; 1996.

3. Lima AAM, Guerrant RL: Persistent diarrhea in children: epidemiology, risk factors, pathophysiology, nutritional impact, and management. Epidemiologic Reviews 1992, 14:222-42.

4. Lima AAM, Moore SR, Barboza MS, Soares AM, Schleupner MA, Newman RD, Sears CL, Nataro JP, Fedorko DP, Wuhib T, Schorling JB, Guerrant RL: Persistent diarrhea signals a critical period of increased diarrhea burdens and nutritional shortfalls: a pro- spective cohort study among children in northeastern Brazil. The Journal of Infectious Diseases 2000, 18 I: 1643-5I.

5. Lumbiganon $P$, Kosalaraksa $P$, Loapaiboon M: Survival of children with AIDS: experience in a university hospital in northestern Thailand. Journal of the Medical Association of Thailand 2000, 83(6):652-6.

6. Emodi IJ, Okafor GO: Clinical manifestations of HIV infection in children at Enugu, Nigeria. Journal of Tropical Pediatrics 1998, 44(2):73-6.

7. Lodha R, Upadhyay A, Vishal K, Kabal SK: Clinical profile and natural history of children with HIV infection. The Indian Journal of Pediatrics 2006, 73(3):20I-4.

8. Tumwine JK, Kekitiinwa A, Bakeera-Kitakia S, Ndeezi G, Downing R, Feng $X$, Akiyoshi DE, Tzipori S: Cryptosporidiosis and microsporidiosis in Ugandan chidren with persistent diarrhea with and without concurrent infection with human immunodeficiency virus. American Journal of Tropical Medicine and Hygiene 2005, 73(5):92I-5.

9. Guarino A, De Marco G: Persistent Diarrhoea. In Pediatric Gastrointestinal Disease BC Decker : USA; 2004:180-193.

10. Handbook IMCI: Integrated Management of Childhood IIIness. 2006 [http://whqlibdoc.who.int/publications/2005/924/546441.pdf]. WHO and UNICEF

II. Amadi B, Mwiya M, Musuku J, Watuka A, Sianongo A, Ayoub A, Kelly $P$ : Effect of nitazoxanide on morbidity and mortality in Zambian children with cryptosporidiosis: a randomized controlled trial. The Lancet 2002, 360(9343): I375-80.

12. Wanke CA, Gerrior J, Blais V, Mayer H, Acheson D: Sucessful treatment of diarrhoeal disease associated with enteroaggregative Escherichia coli in adults infected with human immunodeficiency virus. Journal of Infectious Disease 1998, I 78: 1369-72.

13. Kimmitt PT, Harwood CR, Barer MR: Toxic gene expression by shiga toxin-producing Escherichia coli: the role of antibiotics and the bacterial SOS response. Emerging Infectious Diseases 2000, 6:458-65.

14. Juni $P$, Altman DG, Egger M: Systematic reviews in health care: assessing the quality controlled clinical trials. British Medical Journal 200I, 323(7303):42-6.

15. Bhatnagar S, Bhan MK, Sazawal S, Gupta U, George C, Arora NK, Kashyap DK: Efficacy of a massive dose oral gentamicin therapy in nonbloody persistent diarrhoea with associated malnutrition. Journal of paediatric gastroenterology and nutrition 1992, 12:117-24.

16. Bahl R, Bhandari N, Bhan MK, Saxena M, Bagati A: Efficacy of antimicrobial treatment in non-dysenteric persistent diarrhoea in a community setting. Acta Paediatrica 1996, 85(I I): 1290-4.

17. Alam NH, Bardhan PK, Haider R, Mahalanabis D: Trimethoprimsulphamethaxazole in the treatment of persistent diarrhoea: a double blind placebo controlled clinical trial. Archives of Disease in Childhood 1995, 72(6):483-6.

18. Bartlett AV, Torun B, Morales C, Cano F, Cruz JM: Oral gentamicin is not effective treatment for persistent diarrhea. Acta Paediatrica 1992:149-54.

\section{Pre-publication history}

The pre-publication history for this paper can be accessed here:

http://www.biomedcentral.com/1471-2334/9/24/prepub 